\title{
Alterações no perfil da microbiota bucal durante permanência na UTI: colonização por patógenos respiratórios potenciais
}

\author{
Changes in the oral microbiota profile during ICU stay: colonization by potential \\ respiratory pathogens
}

\section{Alteraciones en el perfil de la microbiota bucal durante permanencia en la UTI: colonización por patógenos respiratorios potenciales}

\author{
Karoline de Souza Chinasso TULIO \\ Roberta Targa STRAMANDINOLI-ZANICOTTI ${ }^{2}$ \\ Acir Jose DIRSCHNABEL ${ }^{3}$ \\ Juliana Lucena SCHUSSEL ${ }^{4}$ \\ José Henrique Schettini WASILEWSKI ${ }^{5}$ \\ Andrea KRELLING ${ }^{6}$ \\ Olair Carlos BELTRAME 6 \\ Carla Regina Worliczeck MARTINS ${ }^{7}$ \\ Laurindo Moacir SASSI ${ }^{8}$
}

${ }^{I}$ Especialização em Estomatologia, Universidade Positivo (UP), Curitiba, PR; Hospital Geral de Curitiba (HGC), Curitiba-PR, Brasil

${ }^{2}$ Especialização em Estomatologia, Universidade Positivo (UP), Curitiba-PR; Hospital Erasto Gaertner Serviço de Cirurgia Bucomaxilofacial, Curitiba-PR, Brasil

${ }^{3}$ Especialização em Estomatologia, Universidade Positivo (UP), Curitiba-PR; Faculdade de Odontologia, UNOESC, Joaçaba-SC, Brasil

${ }^{4}$ Departamento de Estomnatologia, Universidade Federal do Paraná (UFPR), Curitiba-PR, Brasil

${ }^{5}$ Unidade de Terapia Intensiva, Hospital Erasto Gaertner (HEG), Curitiba-PR, Brasil

${ }^{6}$ Serviço de Análises Clínicas, Hospital Erasto Gaertner (HEG), Curitiba-PR, Brasil

${ }^{7}$ Serviço de Infectologia, Hospital Erasto Gaertner (HEG), Curitiba-PR, Brasil

${ }^{8}$ Serviço de Cirurgia Bucomaxilofacial, Hospital Erasto Gaertner Curitiba-PR, Brasil

\section{Resumo}

Introdução: Pacientes hospitalizados em Unidade de Terapia Intensiva(UTI) geralmente mostram má higiene bucal, o que contribui significativamente para o agravamento da contaminação local, com a presença de patógenos respiratórios potenciais. Objetivo: Caracterizar qualitativamente o perfil da microbiota bucal durante permanência na UTI, além da identificação de alterações bucais e salivares. Materiais e métodos: Foi realizado um estudo prospectivo em pacientes internados na UTI de um hospital oncológico, os quais foram avaliados clínica e microbiologicamente após 24 (T1), 72 (T2) e 120 (T3) horas consecutivas à admissão na UTI. Foram identificados os principais patógenos em cada momento e o perfil da microbiota oral foi comparado. Resultados: A amostra final foi de 30 pacientes, 23 homens e 7 mulheres, com idade média de 61 anos. Em T1, 96,67\% dos pacientes apresentaram crescimento de microorganismos patogênicos, sendo identificados 14 tipos diferentes. Em T2 18 tipos de patógenos diferentes e em T3, 21 tipos, dos quais os mais prevalentes nas três coletas foram Staphylococcus não produtor de coagulase e Candida albicans. Clinicamente foram observados presença e progressão do biofilme visível (61\%), cálculo (36,89\%), condição periodontal deficiente (33,11\%). Em relação à condição salivar verificou-se saburra lingual (92,11\%), ressecamento labial (86,67\%), hipossalivação (36,67\%), assialia $(52 \%)$ e escoamento salivar $(8,89 \%)$. Conclusão: O biofilme do dorso de língua de pacientes em UTI pode representar um nicho considerável de patógenos respiratórios potenciais, uma vez que microorganismos etiológicos relacionados à pneumonia nosocomial foram isolados já no primeiro dia de internação, com a colonização subsequente por uma variedade de microorganismos predominantemente gram-negativos

Descritores: Pneumonia Aspirativa; Biofilmes; Infecção Hospitalar; Unidade de Terapia Intensiva.

\section{Abstract}

Introduction: Hospitalized patients receiving treatment at Intensive Care Units (ICU) usually show poor oral hygiene, and may have the mouth and oropharingeal region colonized by pathogens involved in nosocomial pneumonia. The presence of these pathogens may increase the risk for respiratory diseases. OBJECTIVES: The aim of this study was to qualitatively characterize the oral microbiota profile of critical patients during ICU stay, besides the identification of oral and salivary alterations. Materials and Methods: A prospective study was carried out on patients admitted to the ICU from a cancer hospital, who were evaluated clinically and microbiologically (tongue-to-mouth swabs) after 24h (T1), 72h (T2) and within 120 consecutive hours (T3) after ICU admission to the ICU. The main pathogens were identified at each moment and the oral microbiota profile was compared. In addition, the major oral and salivary changes were identified. Results: The final sample consisted of 30 patients, 23 men and 7 women, with a mean age of 61 years. The reasons for hospitalization were $30 \%$ postoperative of oncological surgeries and $70 \%$ of medical emergencies. In $\mathrm{T} 1,96.67 \%$ of the patients presented growth of pathogenic microorganisms, being identified 14 different types. In T2, 18 different pathogen types were identified, and in T3, 21 pathogens, of which the most prevalent Coagulase negative staphylococcus and Candida albicans were the most prevalent in the three collections. It was observed the presence and progression of visible biofilm (61\%), calculus (36.89\%), poor periodontal condition $(33.11 \%)$, partial teeth presence $(26.67 \%)$, total edentulism $(23.33 \%)$, cavities $(10 \%)$, presence of residual root (20\%). In relation to the salivary condition, there was accumulation of lingual (92.11\%), labial dryness (86.67\%), hyposalivation (36.67\%), asialia (52\%) and salivary flow $(8.89 \%)$. Conclusion: The tongue dorsum biofilm of ICU patients may represent a considerable niche of potential respiratory pathogens, since etiological microorganisms related to nosocomial pneumonia were isolated on the first day of hospitalization, with subsequent colonization by a variety of microorganisms predominantly gram-negatives. The introduction of professional care directed to oral health and biofilm control in this group of patients could represent a significant contribution to the reduction of diseases to the health of the patient in the ICU.

Descriptors: Aspiration Pneumonia; Biofilms; Hospital Infection; Intensive Care Unit.

\section{Resumen}

Introducción: Pacientes hospitalizados en UTI generalmente muestran mala higiene bucal, lo que contribuye significativamente al agravamiento de la contaminación local, con la presencia de patógenos respiratorios potenciales. Objetivo: Caracterizar cualitativamente el perfil de la microbiota bucal durante permanencia en la UTI, además de la identificación de alteraciones bucales y salivares. Materiales y métodos: Se realizó un estudio prospectivo en pacientes internados en la UTI de un hospital oncológico, los cuales fueron evaluados clínica y microbiológicamente después de 24 (T1), 72 (T2) y 120 (T3) horas consecutivas a la admisión en la UTI. Se identificaron los principales patógenos en cada momento y el perfil de la microbiota oral fue comparado. Resultados: La muestra final fue de 30 pacientes, 23 hombres y 7 mujeres, con edad media de 61 años. En T1, el 96,67\% de los pacientes presentaron crecimiento de microorganismos patógenos, siendo identificados 14 tipos diferentes. En T2 18 tipos de patógenos diferentes y en T3, 21 tipos, de los cuales los más prevalentes en las tres colectas fueron Staphylococcus no productor de coagulasa y Candida albicans. Se observó la presencia y progresión del biofilme visible (61\%), cálculo (36,89\%), condición periodontal deficiente (33,11\%). En cuanto a la condición salivar se verificó saburra lingual (92,11\%), resecamiento labial (86,67\%), hiposalivación (36,67\%), asialia (52\%) y flujo salivar (8,89\%). Conclusión: El biofilm del dorso de lengua de pacientes en UTI puede representar un nicho considerable de patógenos respiratorios potenciales, ya que microorganismos etiológicos relacionados a la neumonía nosocomial se aislaron ya en el primer día de internación, con la colonización subsecuente por una variedad de microorganismos predominantemente gram-negativa.

Descriptores: Neumonía Aspirativa; Biopelículas; Infección Hospitalaria; Unidad de Terapia Intensiva. 


\section{INTRODUÇÃO}

Pacientes sob cuidados intensivos constituem um grupo de indivíduos em condições graves, potencialmente recuperáveis, que requerem uma equipe multidisciplinar qualificada destinada à assistência e atenção à saúde ${ }^{1}$.

A Unidade de Terapia Intensiva (UTI) representa um ambiente onde o risco de infecções relacionadas à assistência à saúde do paciente se agrava, uma vez que sua condição clínica comprometida associada à variedade de procedimentos invasivos são fatores que o predispõem a tal condição ${ }^{2,3}$. As infecções em UTIs são as complicações mais prevalentes, com índices que variam de 10 a $30 \%$ conforme a população assistida, sendo que a taxa de mortalidade pode ultrapassar $25 \%$.

Considerações importantes têm sido relatadas em estudos onde apontam o biofilme oral como destaque para o desenvolvimento de infecções bacterianas, virais e/ou fúngicas, especialmente em pacientes internados na UTI ${ }^{2,5}$. Tal relação é atribuída à desordem homeostática microbiana bucal ${ }^{5,6}$

Uma representação patológica de referência bucal com grande repercussão hospitalar é a pneumonia nosocomial. Uma de suas principais etiologias é a aspiração do conteúdo presente na orofaringe. Seu estabelecimento se dá com a invasão bacteriana, sendo Acinetobacter spp., Staphylococcus aureus, Escherichia coli, Klebsiella spp., Pseudomonas aeruginosa, Enterobacter spp. e Proteus mirabiis as principais bactérias envolvidas ${ }^{7-9}$. A inalação de aerossóis contaminados e a disseminação hematogênica originada de um foco à distância também são citadas dentre as etiologias, porém com menor frequência ${ }^{10}$.

Estudos recentes sugerem que a pneumonia nosocomial tem como fonte evidente a colonização do biofilme bucal por patógenos, em especial os respiratórios. Observou-se que com o aumento do tempo de internação do paciente na UTI, ocorre aumento da quantidade de biofilme bucal, com colonização de patógenos respiratórios ${ }^{11}$, condição esta que relaciona a microbiota bucal dentre os agentes etiológicos das infecções pulmonares ${ }^{12,13}$.

A colonização da cavidade bucal envolve um processo de interação bacteriana e receptores tissulares, contribuindo para manutenção de uma microbiota abundante e diversificada ${ }^{7,14}$. O número de espécies que compõem o biofilme bucal é vasto, sendo contabilizado aproximadamente $10^{8}$ a $10^{11}$ bactérias $/ \mathrm{ml}$ de biofilme ${ }^{15,16}$. Estas, normalmente, mantém uma relação harmônica com o hospedeiro, embora sua composição possa ser modificada e se tornar patogênica diante das alterações de $\mathrm{PH}$, do potencial de oxi-redução, da disponibilidade de nutrientes e água, da anatomia das estruturas bucais, do fluxo salivar e das substâncias antimicrobianas presentes na saliva ${ }^{17}$. Há ainda considerações relevantes relacionadas à higienização bucal inadequada associada às más condições dentárias, funcionando como abrigo às colônias patogênicas, potencializando assim, o risco de complicações locais e sistêmicas ${ }^{12,18,19}$.

Pacientes em estado crítico de saúde tendem a apresentar alteração da microbiota bucal, enquadrando neste contexto os pacientes comatosos e aqueles que apresentam lesão cerebral severa, uma vez que sua condição os impede de realizar o autocuidado de higiene bucal. Portanto, supõe-se que patógenos respiratórios proliferem com maior facilidade na boca desses pacientes e atinjam vias aéreas inferiores, deixando-os mais susceptíveis ao desenvolvimento de doenças pulmonares ${ }^{20}$. Esta situação favorece o predomínio de microorganismos gram-negativos, constituindo-se de uma flora mais agressiva, a qual pode ser composta por Staphylococcus aureus, Streptococcus pneumoniae, Acinetobacter baumannii, Haemophilus influenza, Pseudomonas aeruginosa, Streptococcus hemolyticus, Escherichia coli e Enterobacter spp. ${ }^{21}$

Diante do exposto, o objetivo do presente estudo foi identificar a presença de patógenos respiratórios potenciais no biofilme de dorso de língua de pacientes hospitalizados, dentro das primeiras 24,72 e 120 horas consecutivas à admissão na UTI, bem como realizar avaliação clínica da condição bucal destes pacientes, agregando a contribuição do cirurgião-dentista junto à equipe multidisciplinar na prevenção de agravos à saúde do paciente neste setor hospitalar.

\section{MATERIAL E MÉTODO}

Foi realizado um estudo prospectivo clínico e microbiológico com pacientes hospitalizados na UTI do Hospital Erasto Gaertner (HEG), na cidade de Curitiba, no Estado do Paraná, durante os meses de março a dezembro de 2013, após aprovação pelo Comitê de Ética em Pesquisa do HEG (P.P. no. 2230). Os pacientes e/ou responsáveis consentiram sua participação, voluntariamente, assinando um formulário TCLE conforme a resolução 196/96Conselho Nacional de saúde do Ministério da Saúde.

Os critérios de inclusão envolveram pacientes oncológicos em estado crítico, com idade superior a 18 anos sem distinção de gênero ou raça. Excluiu-se do estudo os pacientes que estavam em tratamento de tumores na região de cabeça e pescoço ou os quais já realizaram tratamentos prévios nesta região, pacientes com comprometimento de abertura bucal e os transferidos para outros hospitais durante a pesquisa.

Inicialmente foi realizada a coleta de dados biográficos e clínicos dos respectivos prontuários, sempre por um único pesquisador. Os dados 
coletados foram: gênero, idade, dias de internação hospitalar anteriores à UTI e tempo de permanência na UTI. Em seguida, os pacientes foram submetidos à avaliação física bucal, a qual consistiu de: exame extra bucal, exame de mucosa bucal e tecidos moles intra-bucais, análise da condição clínica dos dentes, presença de focos de infecções, avaliação da condição de higiene bucal e saúde gengival.

$\mathrm{Na}$ sequência foi coletada amostra de biofilme do dorso de língua, utilizando hastes flexíveis estéreis $(s w a b)$ que foram transferidos para um tubo de vidro com meio de Stuart para transporte. As coletas foram realizadas em três momentos diferentes: primeira coleta: dentro das primeiras 24 horas de admissão na UTI (T1); segunda coleta: 72 da admissão na UTI (T2); terceira coleta: 120 horas consecutivas após a internação do paciente na UTI (T3).

As amostras colhidas foram identificadas com o nome completo de cada indivíduo e número do prontuário. A etapa microbiológica foi realizada no laboratório de análises clínicas do próprio hospital, onde foi feita a identificação qualitativa dos microorganismos epidemiologicamente relevantes no âmbito das infecções nosocomiais (Staphylococcus spp., Pseudomonas spp., Enterococos spp., fungos, Streptococcus pneumoniae, Acinetobacter baumannii, Haemophilus influenza, Streptococcus hemolyticus, Escherichia coli e Enterobacter spp.). Assim como a resistência a antimicrobianos.

Após homogeneização as amostras foram semeadas pela técnica de esgotamento, onde o material foi depositado nas placas com diferentes meios de cultura, e com o auxílio de uma alça de platina foram realizadas estrias para isolamento das bactérias. Os meios de cultura utilizados foram: Agar chocolate, rico em nutrientes não seletivos para crescimento de bactérias exigentes como Haemophilus influenza, Agar sangue de carneiro, meio não seletivo para identificação principalmente de Staphylococcus e Streptococcus, Agar Mac Conkey, meio seletivo para identificação de bacilos gram-negativos como enterobactérias e não fermentadores de glicose ${ }^{22}$, seguida da incubação 35 graus Celsius por 72 horas.

Para a identificação de gênero e espécie foi realizada a identificação macroscópica dos diferentes tipos de colônias. Foram identificadas bactérias e leveduras, e com o auxílio da coloração de GRAM as bactérias foram classificadas em gram-negativas (BGN) e bactérias gram-positivas (BGP).

As provas bioquímicas para identificação bacteriana e identificação de resistências foram realizadas da seguinte forma: no caso de BGN fermentadores de glucose, a identificação foi feita à partir do Agar Mac onde enterobactérias foram identificadas frente à Kit com diferentes provas bioquímicas. Para as $\mathrm{BGN}$ não fermentadores de glucose, a identificação foi feita à partir do Agar Mac onde foi utilizado a oxidase e Agar cetremide para identificação de pseudomonas. OF glicose, BHI e kit de não fermentador para outros gêneros. Nas situações de BGP catalase positiva, a identificação foi feita à partir do Agar sangue com teste de coagulase para identificar Staphylococcus aureus e não produtor de coagulase. Para BGP catalase negative, a identificação foi feita à partir do Agar sangue onde é definido pela hemólise do meio, utilizado discos de optoquina, bactracina e sulfazotrim além do camp-test para identificação dos diferentes tipos de Streptococcus. Nos casos de Haemophylus influenza a identificação foi feita à partir do Agar chocolate onde é repicado para Agar sangue e utilizado fator X e V. Já para as leveduras, primeiramente realizou-se o teste do tubo germinativo para identificação de Candida albicans e depois um cromoagar para outras espécies.

A identificação de resistências bacterianas do tipo enterobactérias produtoras de betalactamases de espectro expandido (ESBL) foi observada por meio de testes com discos de aproximação; bem como, pseudomonas e acinetobacter pan resistentes; Staphylococcus aureus resistentes a meticilina (MRSA) e enterococcus resistentes a vancomicina (VRE).

No teste de sensibilidade aos antibióticos foi utilizado o teste da difusão dos discos ${ }^{23}$, com interpretação para sensível (S), intermediário (I) ou resistentes (R) de acordo com as normas estabelecidas pelo Control Laboratoty Standart Institute $^{24}$.

Os dados obtidos foram anotados em uma ficha elaborada para a pesquisa com os seguintes dados: identificação, idade, gênero, número do prontuário, data e setor hospitalar de internação, data de avaliação odontológica, tempo de permanência na UTI, motivo da internação, tipo de material colhido para exame microbiológico, agentes infecciosos isolados, diagnóstico clínico, topografia do tumor, principais medicações em uso, comorbidades, estado geral, consciência, comunicação verbal, tipo de dieta, presença de dispositivos invasivos como tubo endotraqueal, sonda gástrica, sonda enteral, cateter venoso central. Tais dados foram digitados em uma planilha eletrônica do EXCEL, analisados e distribuídos em planilhas do mesmo programa para confecção de tabelas e gráficos para demonstração dos resultados. Foi realizada uma estatística descritiva da incidência dos patógenos identificados nas três coletas, além da condição bucal dos pacientes.

\section{RESULTADOS}

O estudo envolveu 79 pacientes submetidos à primeira coleta, 51 à segunda coleta e 30 à terceira. A diferença de pacientes nos três momentos se explica 
em função da evolução clínica, havendo 10 óbitos e 18 altas antes da segunda coleta e 9 óbitos e 12 altas antes da terceira coleta.

Do total dos 30 pacientes que foram submetidos às três coletas, $23(76,67 \%)$ eram do gênero masculino e $7(23,33 \%)$ do gênero feminino, com idade média de 61 anos, com variação entre 22 a 91 anos. A média de dias de internação hospitalar anteriormente à UTI foi de 4 dias, variando de 1 a 27 dias. Na UTI a média de permanência dos pacientes avaliados foi de 11 dias, sendo o tempo máximo de 28 dias. Os participantes das três coletas tiveram como motivo de internação: $30 \%$ pós-operatório de cirurgias oncológicas e $70 \%$ urgências médicas.

Em relação aos microorganismos isolados no biofilme de dorso de língua dos 30 pacientes em T1, foram encontrados os seguintes resultados $96,67 \%$ apresentaram crescimento de microorganismos patogênicos na primeira coleta sendo identificados 14 tipos diferentes, dos quais os mais prevalentes foram: Staphylococcus não produtor de coagulase 53,33\% (16), Candida albicans 10\% (3), Staphylococcus aureus resistente a meticilina-MRSA $6,67 \%$ (2), Escherichia coli-ESBL 6,67\% (2) e Moraxella catarrhalis $10 \%$ (3). Destes, os Staphylococcus aureus resistente à meticilina-MRSA $(6,67 \%) \mathrm{e}$ Escherichia coli-ESBL (6,67\%) representam classicamente os microorganismos etiológicos relacionados à pneumonia nosocomial (Gráfico 1).

Em T2 foram identificados 18 tipos de patógenos (Gráfico 1), sendo os de maior representatividade os Staphylococcus não produtor de coagulase $30 \%$ (9), Candida albicans 16,67\% (5), Staphylococcus aureus resistente a meticilina-MRSA 13,33\% (4), Acinetobacter baumanii 10\% (3), Staphylococcus aureus 6,67\% (2), Moraxella catarrhalis $6,67 \%$ (2), Enterobacter aerogenesmultisensivel 6,67\% (2), Serratia marcescensmultisensivel $6,67 \% \quad(2), \quad$ Klebsiella oxytocamultisensivel 6,67\% (2).

Em T3 foram identificados 21 patógenos (Gráfico 1), dos quais apresentaram maior prevalência: Staphylococcus não produtor de coagulase $30 \%$ (9), Candida albicans $13,33 \%$ (4), Staphylococcus aureus resistente a meticilina-MRSA 13,33\% (4), Acinetobacter baumanii 6,67\% (2), Klebsiella pneumoniae- ESBL 10\% (3), Moraxella catarrhalis $6,67 \%$ (2), Enterobacter aerogenesmultisensivel 6,67\% (2), Enterobacter cloacaemultisensivel 6,67\% (2), Acinetobacter baumaniimultirresistente $6,67 \%$ (2).

Dentre as condições odontológicas detectadas por meio do exame clínico dos 30 pacientes avaliados, detectou-se a presença e progressão do biofilme visível $(61 \%)$, cálculo $(36,89 \%)$, condição periodontal deficiente $(33,11 \%)$, presença parcial de dentes $(26,67 \%)$, edentulismo total $(23,33 \%)$, lesões cariosas $(10 \%)$, presença de raízes residuais $(20 \%)$ conforme os dados apresentado no Gráfico 2.

Quanto à avaliação clínica da condição salivar dos pacientes avaliados, foi detectado (Gráfico 3): acúmulo de saburra lingual (92,11\%), ressecamento labial $(86,67 \%)$, hipossalivação $(36,67 \%)$, assialia $(52 \%)$ e escoamento salivar $(8,89 \%)$

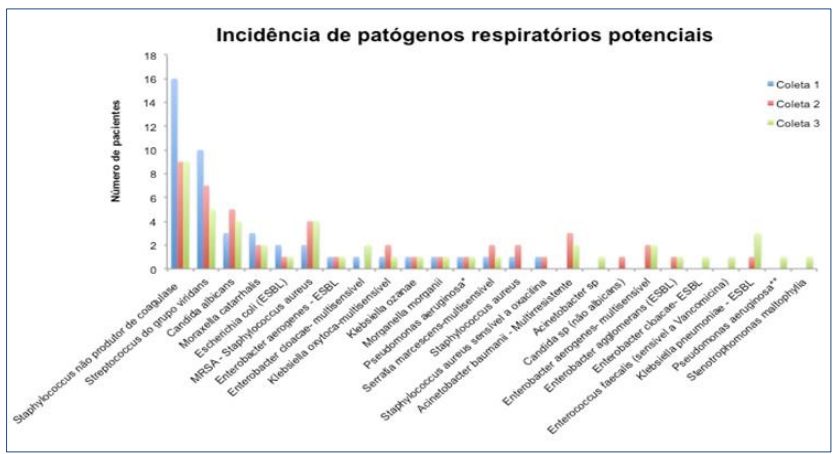

Gráfico1: Incidência de patógenos respiratórios potenciais em pacientes internados na UTI do Hospital Erasto Gaertner, Curitiba-PR.

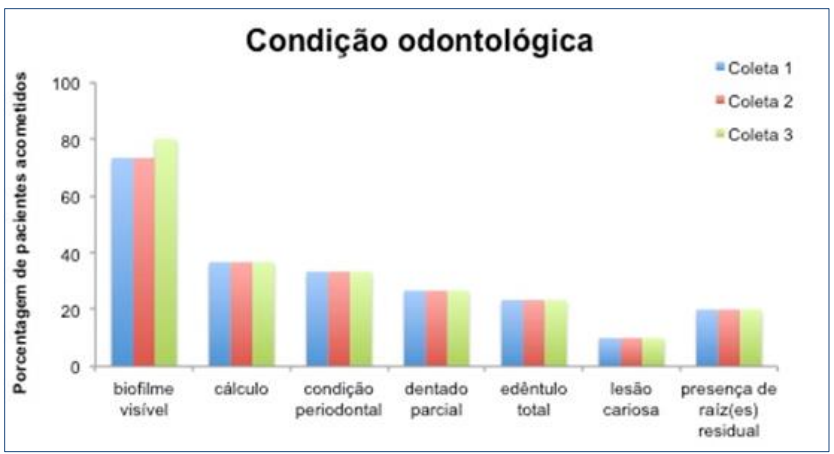

Gráfico 2: Condição odontológica dos pacientes internados na UTI do Hospital Erasto Gaertner, Curitiba-PR.

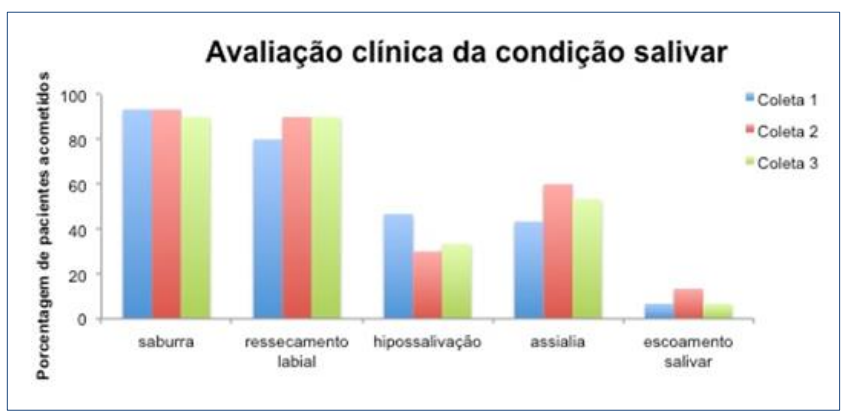

Gráfico 3: Avaliação clínica da condição salivar dos pacientes internados na UTI do Hospital Erasto Gaertner, Curitiba-PR.

\section{DISCUSSÃO}

Estudos recentes sugerem que a pneumonia nosocomial tem como fonte prevalente a colonização do biofilme bucal por patógenos, em especial os respiratórios. Observa-se que a quantidade de biofilme bucal em pacientes de UTI aumenta com o tempo de internação, concomitantemente ocorre aumento de patógenos respiratórios potenciais os quais colonizam o biofilme bucal ${ }^{11 .}$ A relação entre os fatores tempo de internação e prevalência de colonização patogênica de biofilme bucal é atribuída como fator contribuinte para o aumento dos índices 
de casos de pneumonia ${ }^{10}$. Os resultados desta pesquisa corroboram com estes autores, uma vez que após 72 e 120 horas de admissão na UTI houve aumento do número de microorganismos potencialmente patogênicos ao trato respiratório, representando um risco à recuperação da saúde dos pacientes internados na UTI.

O acúmulo de biofilme bucal também foi considerado nos estudos em que foi observado um crescente aumento do número de microorganismos em culturas orais a partir do primeiro dia de internação na $\mathrm{UTI}^{21}$. Resultados estes que corroboram com outros dados obtidos na literatura ${ }^{25}$, diante da observação de colonização em cavidade bucal no primeiro dia de ventilação mecânica em $80 \%$ dos pacientes intubados. Tais autores atribuem à cavidade bucal, fonte primária para o desenvolvimento de pneumonia associada à ventilação mecânica. Mudanças na composição da flora bucal com predomínio de $\mathrm{BGN}$, frequentes agentes de infecções hospitalares, foram detectadas dentro de 48 horas após a internação na $\mathrm{UTI}^{26}$. Dados estes que reforçam os resultados obtidos no presente estudo, uma vez que 14 tipos de patógenos foram identificados dentro das primeiras 24 horas de internação do paciente na UTI, bem como sua progressão a partir de 48 horas, onde foram identificados 18 tipos e 21 tipos a partir de 120 horas de internação.

Patógenos respiratórios não são usualmente encontrados na flora indígena bucal de pacientes saudáveis, embora aqueles originários do meio ambiente hospitalar tenham potencial para colonizar as superfícies dos dentes, as próteses, a mucosa bucal e respectivos biofilmes. Tal colonização patogênica nestas superfícies pode ser facilitada pela diminuição parcial, ou total, da salivação e do $\mathrm{PH}$ da saliva, fatos estes encontrados em pacientes de UTI devido à medicação administrada ${ }^{19}$. Nesta pesquisa foram observadas condições de restrição salivar, tais como hipossalivação e assialia, podendo-se relacionar com a administração de polifármacos com efeitos colaterais xerostômicos, características que condizem com os dados científicos supracitados e tendem a favorecer a colonização do meio por patógenos respiratórios potenciais.

A flora bucal de indivíduos sadios é composta predominantemente de BGP, sendo os Estreptococos viridans os agentes de maior representatividade, porém pacientes em estado crítico tendem a apresentar mudanças na composição da flora, havendo predomínio de microorganismos anaeróbios gram-negativos, incluindo patógenos comumente responsáveis pela pneumonia nosocomial $^{27}$, tais como Staphylococcus aureus, Streptococcus pneumoniae, Acinetobacter baumanii, Influenzae Haemophilus e Pseudomonas aeruginosa, Escherichia coli, Klebsiella spp., Enterobacter spp. e
Proteus mirabiis ${ }^{7-9,21}$. Tais dados ratificam os resultados obtidos nesta pesquisa, uma vez que foi observada a progressiva ausência de Streptococcus do grupo viridans conforme as consecutivas coletas, chegando $83,33 \%$ dos indivíduos livres de tal colonização no biofilme de dorso de língua, bem como a variedade de patógenos identificados.

O Staphylococcus spp. normalmente coloniza a pele e mucosas do corpo humano mantendo uma relação harmônica, de forma comensalista, com o hospedeiro. Todavia, diante de condições de vulnerabilidade do indivíduo, sérias e frequentes infecções nosocomiais podem ocorrer ${ }^{19}$. Em um estudo americano epidemiológico de pneumonia associada aos cuidados de saúde observou-se que o patógeno dominante em todos os tipos de pneumonia foi o Staphylococcus aureus, apresentando maior ocorrência nos grupos da doença adquirida em ambiente hospitalar. Além de que tal patógeno foi o único que apresentou significativa correlação com os casos de mortalidade ${ }^{28}$. Dados estes que vão de encontro aos dados da "European Infection Control" que atribui ao $S$. aureus a representação de $30 \%$ dos casos de pneumonia nosocomial ${ }^{29}$. Porém, há muito o que se considerar em estudos relacionados à identificação de patógenos alguns fatores dependentes tais como o perfil epidemiológico de cada instituição hospitalar envolvida além da variação entre as regiões demográficas ${ }^{30}$, justificando os resultados obtidos nesta pesquisa onde a predominância deste patógeno não foi significativa, uma vez que sua identificação se deu até a segunda coleta em 6,67\% dos casos com posterior ausência.

O Staphylococcus aureus pode causar infecções superficiais e até algumas disseminadas com elevada gravidade, cuja importância clínica está relacionada à incidência de infecções hospitalares graves causadas por amostra multirresistente ${ }^{30}$. Em se tratando da resistência aos antibióticos os Staphylococcus aureus resistente a Meticilina (MRSA) representam $30 \%$ de todos os S. aureus isolados nos hospitais dos EUA e Europa, embora possam encontrar taxas de até $55 \%$ em unidades de terapia intensiva ${ }^{28}$. O resultado deste estudo demonstrou que a colonização de dorso de língua por MRSA foi estabelecido logo na primeira coleta e dobrou a partir da segunda, com o acometimento de $13,33 \%$ dos pacientes.

Dentre as inúmeras condições significativas inerentes aos pacientes sistemicamente debilitados, está o aumento dos níveis de protease nas secreções orais, situação esta que tende a remover das superfícies celulares epiteliais um importante mecanismo de defesa do organismo, a fibronectina, cuja função é impedir a adesão de bactérias patogênicas na mucosa da boca e da traquéia, fator determinante ao favorecimento da presença de patógenos de maior virulência na orofaringe $\mathrm{e}^{31}$. 
Considerando os respectivos estudos, a presença de um número significativo de microorganismos patogênicos encontrados nesta pesquisa, pode ser justificada pela degradação deste importante mecanismo de defesa do organismo.

Outras condições que tendem a contribuir para vulnerabilidade do paciente às complicações sistêmicas na UTI, além de dificultar as ações direcionadas ao cuidado oral no paciente intubado são os problemas bucais preexistentes, tais como dentes cariados, perdidos e acúmulo de placa bacteriana $^{22}$. Tão $\log 0$ a atenção indevida à higienização oral resulta no aumento da quantidade e complexidade do biofilme bucal, o que tende a favorecer a interação bacteriana entre bactérias indígenas e patógenos respiratórios ${ }^{5,7,32}$. Tal situação corrobora com os dados obtidos nesta pesquisa, uma vez que, considerável representação dos pacientes avaliados já apresentavam alguma condição bucal atípica, tais como: condição periodontal deficiente,cálculo, lesões de cárie, presença de raízes residuais,ou seja,um meio favorável aos microorganismos, diante do primeiro exame clínico odontológico,bem como o aumento de biofime visível foi detectado consecutivamente aos dias de internação.

Alguns pesquisadores consideram por meio de sua compilação de estudos que intervenções de higiene oral e frequente cuidado profissional à saúde bucal poderiam contribuir para evitar os riscos de pneumonia e diminuir internações hospitalares bem como a utilização de recursos em saúde ${ }^{32}$. Tais afirmações são evidentes e refletem as conclusões obtidas nesta pesquisa, uma vez observado que intervenções odontológicas preventivas poderiam ter repercussões representativas no decorrer do período de internação do paciente com consequente reflexo na sua recuperação.

\section{CONCLUSÃO}

O biofilme do dorso de língua de pacientes em UTI pode representar um nicho considerável de patógenos respiratórios potenciais, uma vez que micro-organismos etiológicos relacionados à pneumonia nosocomial foram isolados já no primeiro dia de internação, com a colonização subsequente por uma variedade de micro-organismos predominantemente gram-negativos.

\section{REFERÊNCIAS}

1. Amaral CFS. Infecção Hospitalar. Rio de Janeiro: Medsi: 2001. p.135.

2. Gusmão MEN, Dourado I, Fiaccone RL. Nosocomial pneumonia in the intensive care unit of a Brazilian university hospital: an analysis of the time span from admission to disease onset. Am J Infect Control. 2004; 32(4):209-14.

3. Saba-Chujfi E, Pereira SAS, Dias LZS. Inter- relação das doenças periodontais com as doenças cardiovasculares e cerebrovasculares isquêmicas. R Periodontia. 2007; 17(2):21-31.

4. Souza PR. Análise microbiológica e genéticomolecular da biota orotraqueal de paciente crítico: subsídios na prevenção da pneumonia associada à ventilação mecânica [tese]. Ribeirão Preto: Escola de Enfermagem de Ribeirão Preto, Universidade de São Paulo; 2009.

5. Costerton JW, Stewart PS, Greenberg EP. Bacterial biofilm: a common cause of persistent infections. Science. 1999; 284(5418):1318-22.

6. Scannapieco FA, Bush RB, Paju S. Associations between periodontal disease and risk for nosocomial bacterial pneumonia and chronic obstrutive pulmonary disease: A systematic review. Ann Periodontol. 2003; 8(1):54-69.

7. Pace MA, Watanabe E, Facceto MP, Andrade D. Staphylococcus spp. na saliva de pacientes com intubação orotraqueal. Rev Panam. Infectol. 2008; 10(2): 8-12.

8. Rothman A. Barbas C. S.V., Camargo L.F.A. Infecções respiratórias em UTI, em: Knobel ECondutas no Paciente Grave. 2. ed. São Paulo: Atheneu; 1999. p.771-80.

9. Scannapieco FA, Rosa Junior C. Doenças periodontais versus doenças respiratórias. In: Periodontia Médica. São Paulo: SENAC; 2004. p.391-409.

10. Fourrier F, Duvidier $B$, Boutigny $H$. Colonization of dental plaque: a source of nosocomial infections in intensive care unit patient. Critical Care Med. 1998; 26 (2):301-8.

11. Sannapieco FA. Relação entre doença periodontal e doenças respiratórias. In:Rose LE, Genco RJ, Mealy BI. Medicina Periodontal. São Paulo: Santos; 2002.p. 83-97.

12. Amaral SM, Cortês AQ, Pires FR. Pneumonia nosocomial: importância do microambiente oral. J Bras Pneomol. 2009; 35(11):1116-24.

13. Scannapieco FA, Stewart EM, Mylotte JM. Colonization of dental plaque by respiratory pathogens in medical intensive care patients. Crit Care Med. 1992; 20(6):740-45.

14. Fernandes A, Fernandes MAV, Ribeiro NF. Infecções hospitalares e suas interfaces na área de Saúde. São Paulo: Atheneu; 2000.

15. Lotufo RFM, Pannuti CM. Efeitos diretos dos patógenos bucais nas condições sistêmicas. In: Brunetti MC. Periodontia Médica. São Paulo: SENAC; 2004. p.42-57.

16. Safdar N, Crnich CJ, Maki DG. The patogenisis of ventilador associated pneumonia: its relevance to developing effective strategieof prevention. Respir Care. 2005; 50(6):725-41.

17. Lindhe J, Karring $\mathrm{T}$, Lang NP. Tratado de periodontia clínica e implantologia oral. 4. ed. 
Rio de Janeiro: Guanabara Koogan; 2005. p.105-47.

18. Morais TMN, Silva A, Avi ALRO, Souza PHR, Knobel E, Camargo LFA. A importância da atuação odontológica em pacientes internados em unidade de terapia intensiva. RBTI. 2006;18(4):412-17.

19. Oliveira LCBS, Carneiro PPM, Fischer RG, Tinoco BEM. A presença de patógenos respiratórios no biofilme bucal de pacientes com pneumonia nosocomial. RBTI. 2007; 19 (4):428-33.

20. Cecon F, Ferreira LEN, Rosa RT, Gursky LC, Carvalho AP, Samaranayake LP, Rosa EAR. Time-related increase of staphylococci, enterobacteriaceae and yeasts in the oral cavities of comatose patients. J Microbiol Immunol Infect. 2010; 43(6):457-63.

21. Munro CL, Grap MJ. Oral health and care in the intensive care Unit State of the Science.Am J Crit Care. 2004; 13(1):25-34.

22. Ito IY, Costa A, Barachinni O. Emprego da gema de ovo no isolamento de Sthaphylococcus aureus. Ann Microbiol. 1969; 16:189-92.

23. Bauer AW, Kirby WMM, Sherris JC, Turck M. Antibiotic susceptibility testing by a standardized single disk method. J Clin Pathology. 1966; 45(4):493-96.

24. Padronização dos testes de sensibilidade a antimicrobianos por disco-difusão: Norma aprovada; janeiro 2005. Disponível em URL: http://www.anvisa.gov.br/servicosaude/manuais/ clsi/clsi_OPASM2-A8.pdf

25. Cardeñosa CJA, Sole-Violan J, Benitez B. A Role of different routs of traqueal colonization in the development of pneumonia in patients receiving mechanical ventilation. Chest. 1999; 116(2):462-70.

26. Jones DJ, Munro CL \& Mary Jo Grap MJ, Natural history of dental plaque accumulation in mechanically ventilated adults: a descriptive correlational study. Intensive Crit Care Nurs. 2011; 27(6):299-304.

27. Araújo RJG, Oliveira LCG, Hanna LMO, Correa AM, Carvalho LHV, Alvares NLF. Análise de percepções e ações de cuidados bucais realizados por equipes de enfermagem realizados em unidades de tratamento intensivo. RBTI. 2009; 21(1):38-44.

28. Kollef MH, Shorr A, Tabak YP, Gupta V, Lyu LZ, Johannes RS. Epidemiology and outcomes of health care associated pneumonia. Chest. 2005; 128(6):3854-62.

29. Cardoso RL. Pneumonia em pacientes sob ventilação mecânica por Staphylococcus aureus resistentes a meticilina internados em UTI de adultos: aspectos microbiológicos e clínicos [dissertação]. Minas Gerais: Universidade Federal de Uberlândia; 2007.

30. Calcagnotto L, Nespolo CR, Stedile NRL. Resistência antimicrobiana em microrganismos isolados do trato respiratório de pacientes internados em unidade de terapia intensiva. Arq Catarin Med. 2011; 40(3):77-83.

31. Pear S, Stoessel K, Shoemake S. Cuidados bucais são cuidados críticos. Kimberly-Clark Health Care Education. 2007;1-30.

32. Azarpazhooh A, Leake JL. Systemic review of the association between respiratory diseases and oral health. J Periodontol. 2006; 77(9):1465-82.

\section{CONFLITO DE INTERESSES}

Os autores declaram não haver conflitos de interesse.

\section{AUTOR PARA CORRESPONDENCIA}

\section{Roberta Targa Stramandinoli-Zanicotti}

robertastramandinoli@yahoo.com.br 